\title{
Integumentary Refine Fluxing Material for Melting of Copper Matrix Composite Alloys
}

\author{
Vladimir G. Babkin* and Alina I. Trunova \\ Siberian Federal University \\ 79 Svobodny, Krasnoyarsk, 660041, Russia
}

Received 22.02.2016, received in revised form 19.03.2016, accepted 17.07.2016

The requirements for intergumentary refining fluxing material, used for melting of copper matrix composite alloys (CA) are investigated. It offers the most effective composition of flux, not only protecting the melt from oxidation by oxygen, but also from the penetration of hydrogen, which can significantly improve the mechanical properties of the finished product.

Keywords: the copper matrix composite alloys, the intergumentary fluxing material, the synthesis of reinforcing phase.

Citation: Babkin V.G., Trunova A.I. Integumentary refine fluxing material for melting of copper matrix composite alloys, J. Sib. Fed. Univ. Eng. technol., 2016, 9(6), 836-844. DOI: 10.17516/1999-494X-2016-9-6-836-844.

\section{Покровно-рафинирующие флюсы}

\section{для выплавки медематричных}

композиционных сплавов

\section{В.Г. Бабкин, А.И. Трунова}

Сибирский федеральный университет Россия, 660041, Красноярск, пр. Свободный, 79

Исследованы требования, предъявляемые $\kappa$ покровно-рафинирующим флюсам, применяюшимся при выплавке медематричных композиционных сплавов (КС). Предложен наиболее эффективный состав флюса, защищающего расплав не только от окисления кислородом, но и от проникновения водорода, что позволяет значительно повысить механические свойства готового изделия.

Ключевые слова: медематричные композиционные сплавы, покровно-рафинируюший флюс, синтез упрочняющих фаз.

(c) Siberian Federal University. All rights reserved

* Corresponding author E-mail address: lpiomd@mail.ru 
Композиционные сплавы на основе меди, упрочненные частицами карбидов, боридов и других тугоплавких соединений, применяются в электротехнике в качестве контактного материала для высоковольтных выключателей, электродов сварочных машин, силовых кабелей и других изделий электротехнического назначения.

Наиболее эффективным способом получения литых композиционных материалов является метод синтеза упрочняющей фазы в матричном расплаве $[1,2]$. Однако плавка меди и медных сплавов в открытых плавильных печах приводит к насыщению сплава кислородом, что существенно снижает механические характеристики литых изделий (на рис. 1 показано снижение пластичности литой меди при насыщении ее кислородом) и скорость формирования упрочняющих ультрадисперсных фаз в реакциях in-situ. В частности, растворение хрома при синтезе в расплаве меди упрочняющих фаз происходит замедленно, что обусловлено ограниченной растворимостью хрома в меди. При этом хром активно окисляется с образованием плотной оксидной пленки. В результате угар хрома может составлять $60 \%$ [3].

В предыдущих работах методом термического анализа нами было исследовано насыщение расплава меди кислородом в кислородсодержащей газовой фазе и возможность его раскисления наноразмерным алмазографитом, входящим в состав реакционной смеси, применяемой для синтеза карбида хрома при получении медематричных композитов [4]. Показана высокая рафинирующая способность алмазографита, позволяющая существенно повысить пластичность меди и медематричных композитов. Вместе с тем снижение содержания кислорода в меди приводит к повышению растворимости водорода в обычных условиях плавки, что способствует образованию пористости в литых изделиях при кристаллизации. Поэтому одним из основных условий получения качественных композиционных сплавов является ведение процесса плавки под защитным слоем покровного флюса. Для защиты меди и сплавов от окисления чаще всего в качестве материалов покровного слоя применяют древесный уголь в виде кусков до 30-80 мм, восстанавливают $\mathrm{Cu}_{2} \mathrm{O}$ по реакциям (1), (2) [5]:

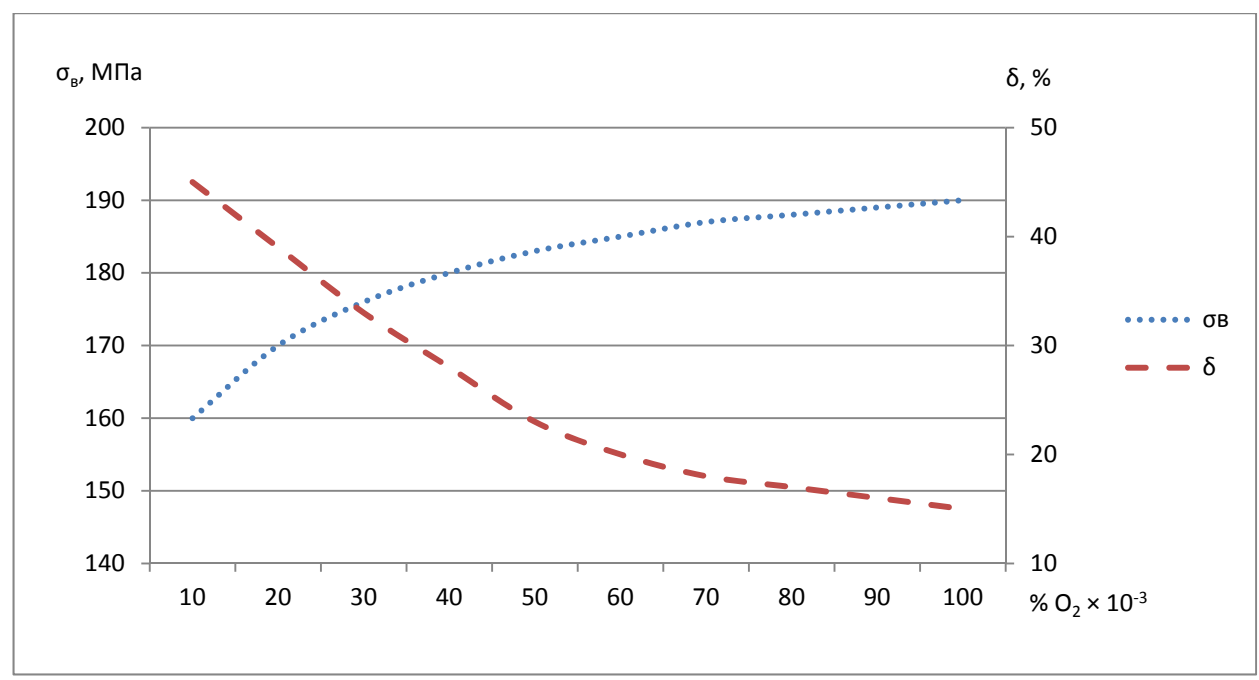

Рис. 1. Влияние насыщения литой меди кислородом на предел прочности $\left(\sigma_{\mathrm{B}}\right)$ и относительное удлинение ( $\delta$ ) 


$$
\begin{array}{ll}
2 \mathrm{Cu}_{2} \mathrm{O}+\mathrm{C} \rightarrow 4 \mathrm{Cu}+\mathrm{CO}_{2}, & \Delta G_{1100}^{0}=-221,4 \text { кДж/моль, } \\
\mathrm{Cu}_{2} \mathrm{O}+\mathrm{CO} \rightarrow 2 \mathrm{Cu}+\mathrm{CO}_{2}, & \Delta G_{1100}^{0}=-99,4 \text { кДж/моль. }
\end{array}
$$

Применение для раскисления меди наноразмерного алмазографита позволяет увеличить площадь поверхности соприкосновения раскислителя с расплавом и ускорить процесс восстановления.

Углеродотермическое восстановление более прочных оксидов $\mathrm{SiO}_{2}, \mathrm{PbO}, \mathrm{CaO}, \mathrm{Al}_{2} \mathrm{O}_{3}$ и др., имеющихся в технической меди и медном ломе, не происходит, о чем свидетельствует термодинамический анализ реакций (3-4):

$$
\begin{array}{ll}
\mathrm{CaO}+3 \mathrm{C}=\mathrm{CaC}_{2}+\mathrm{CO}, & \Delta G^{0}=433836-192,2 \mathrm{~T}, \text { Дж, } \\
\mathrm{Si}_{2} \mathrm{O}+3 \mathrm{C}=\mathrm{SiC}+2 \mathrm{CO}, & \Delta G^{0}=526573-344,2 T, \text { Дж, } \\
2 / 3 \mathrm{Al}_{2} \mathrm{O}_{3}+3 \mathrm{C}=1 / 3 \mathrm{Al}_{4} \mathrm{C}_{3}+2 \mathrm{CO}, & \Delta G^{0}=804703-321,5 T, \text { Дж. }
\end{array}
$$

Для этих реакций температуры, при которых $\Delta \mathrm{G}^{0}=0$, соответственно составляют 2257 , $1530,2503 \mathrm{~K}$.

Целью настоящей работы является исследование и разработка состава флюса, обеспечивающего не только раскисление меди, но и рафинирование металла от содержащихся в нем примесей, что особенно актуально при утилизации бракованных слитков и переплава вторичного сырья. Температура плавления флюса не должна превышать $900{ }^{\circ} \mathrm{C}$, и при температуре приготовления композиционных сплавов 1200-1300 ${ }^{\circ} \mathrm{C}$ флюс должен иметь достаточную жидкотекучесть и хорошую кроющую способность. Физико-химические свойства флюса должны обеспечивать его агрессивность, т.е. растворять оксиды примесей металлов, а также растворять оксид хрома и улучшать его усвоение. Во флюсе не должны находиться легколетучие хлориды и фториды, что особенно важно с экологической точки зрения. Составляющие флюса должны быть достаточно инертны к углеродсодержащему покрову, а также к компонентам расплава.

Одновременно решалась задача защиты расплава меди от насыщения водородом и получения высококачественных медематричных композиционных сплавов. В качестве эффективного раскислителя в составе покровно-рафинирующего флюса применили наноразмерный алмазографит, который ускоряет процесс восстановления оксида меди благодаря высокой удельной поверхности и химической активности. Поскольку углерод не восстанавливает термодинамически прочные оксиды, имеющиеся в расплаве или образовавшиеся в результате окисления металлических примесей, для их удаления обычно применяют фториды кальция и натрия, которые при $800{ }^{\circ} \mathrm{C}$ образуют эвтектику. Для снижения токсичности этой системы рекомендуется вместо $\mathrm{NaF}$ применять криолит $\left(\mathrm{Na}_{3} \mathrm{AlF}_{6}\right)$. Солевой сплав эвтектического состава $\left(80 \% \mathrm{CaF}_{2}+\right.$ $20 \% \mathrm{Na}_{3} \mathrm{AlF}_{6}$ ) плавится при $900{ }^{\circ} \mathrm{C}$ и образует при плавке меди жидкий покров, изолирующий металл от атмосферы. В этом случае обеспечивается достаточно надежная защита расплава меди от окисления, поскольку этот процесс будет контролироваться диффузией катионов металлов через слой флюса. Флюс содержит фторид кальция $\mathrm{CaF}_{2}$ и криолит, которые хорошо растворяют оксидные включения. Поверхностное натяжение фторида кальция составляет 250 мДж/ $\mathrm{M}^{2}$, а криолита - 148 мДж/м2. Поверхностное натяжение флюса системы $80 \mathrm{CaF}_{2}$ 
$-20 \mathrm{Na}_{3} \mathrm{AlF}_{6}$, определенное методом аддитивности, составило 230 мДж/м² [6]. Криолит в этой системе является поверхностно-активным компонентом.

Известно, что удаление оксидных неметаллических включений определяется соотношением поверхностных энергий (б) на границах раздела фаз $\sigma_{\mathrm{Cu-в}}, \sigma_{\mathrm{Cu- \phi}}$ и $\sigma_{\phi-\mathrm{s}}$. С термодинамической точки зрения этот процесс обусловлен убылью свободной энергии системы.

Убыль свободной энергии Гиббса $[-\Delta \mathrm{G}]$ в процессе удаления включений:

$$
\frac{\Delta G}{\omega}=\sigma_{C u-\phi}+\sigma_{\phi-\mathrm{B}}+\sigma_{C u-\mathrm{B}},
$$

где $\sigma_{C u-\phi}, \sigma_{\phi-в}, \sigma_{C u-\text { в }}$ - межфазное натяжение на границе фаз соответственно жидкий металл-жидкий флюс, жидкий флюс-оксидная фаза (включение), жидкий металл-оксидная фаза.

$$
\begin{array}{r}
\Delta G<0 \text {, если } \sigma_{C u-\mathrm{B}}>\sigma_{C u-\phi}+\sigma_{\phi-\mathrm{B}} \\
\sigma_{C u-\mathrm{B}}>\sigma_{C u-\phi}>\sigma_{\phi-\mathrm{B}} .
\end{array}
$$

Работа разделения фаз, отнесенная к единице поверхности их раздела $\left(\mathrm{W}_{\mathrm{a}}\right)$, может служить основой характеристикой экстрагирования включения флюсом.

Условия экстрагирования включения флюсом:

$$
W_{a(\phi-\mathrm{B})}>W_{a(\mathrm{Cu- \phi )}}>W_{a(\mathrm{Cu- \textrm {B } )})} .
$$

Для оценки рафинирующей способности флюса в работе исследовали физико-химические свойства солей, входящих в состав комплексного флюса, и кинетику его растекания по поверхности оксидных включений. Установлено, что криолит в составе флюса действует как поверхностно-активное вещество, снижающее межфазное натяжение на границе металл-флюс и флюс-включение и улучшает смачивание включений, а фториды кальция в этой системе являются поверхностно-неактивными, повышая межфазное натяжение на границе с флюсом и металлом. Присутствующие в шихте оксиды, нерастворимые в металле, всплывают на поверхность, смачиваются флюсом и переходят в шлак. Следует отметить, что фториды Al и Са могут в небольших количествах растворять $\mathrm{Al}_{2} \mathrm{O}_{3}, \mathrm{SiO}_{2}, \mathrm{PbO}, \mathrm{ZnO}, \mathrm{SnO}_{2}$ и др. При этом вязкость шлака повышается и его можно практически полностью удалить с поверхности металлического расплава. Наличие графита в составе флюса обеспечивает съем шлака с минимальным захватом жидкого металла с зеркала ванны печи.

Оксидные включения удаляются в том случае, если они смачиваются флюсом лучше, чем жидким металлом. На рис. 2 видим, что скорости растекания флюса по подложкам из оксидов в первые $2 \cdot 10^{-2}$ с весьма велики и составляют $17-25 \mathrm{~cm} / \mathrm{c}$. В этот период времени наиболее интенсивно происходит изменение контактных углов. Скорость смачивания и растекания заметно уменьшается со временем и через 0,04-0,1 с становится незначительной. Значения контактных углов в этой области приняты для расчета работы адгезии флюса включением.

Для расчета поверхностных натяжений флюса к включению температурные зависимости поверхностного натяжения флюса системы $80 \mathrm{CaF}_{2}+20 \mathrm{Na}_{3} \mathrm{AlF}_{6}$ и краевых углов солевого расплава на графите и некоторых оксидах определяли из соотношения [6]:

$$
-839-
$$




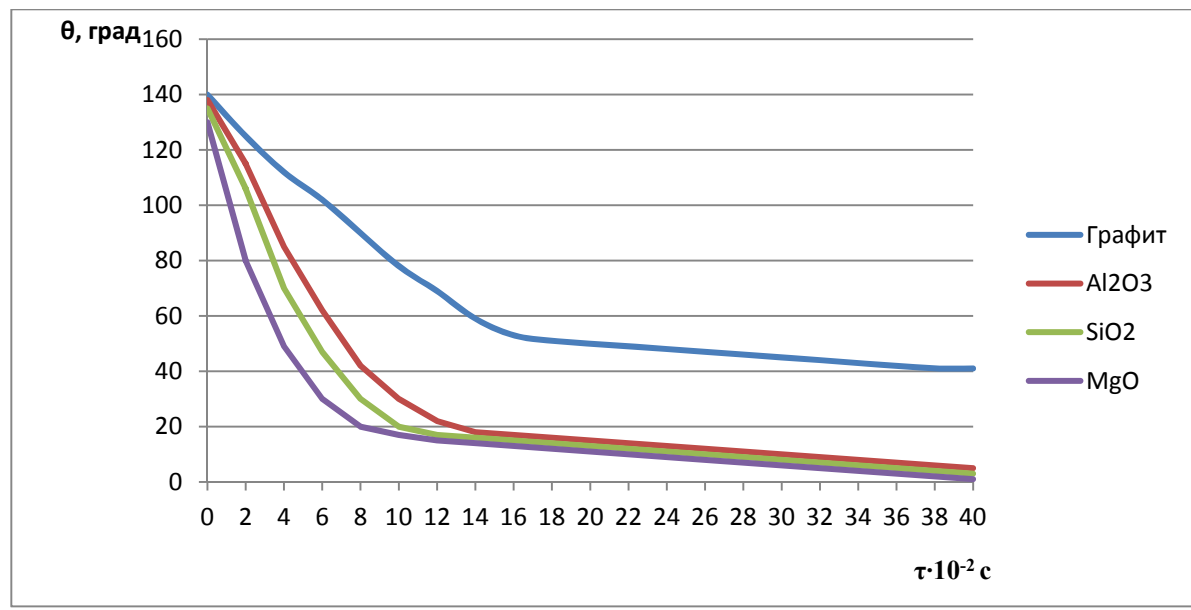

Рис. 2. Изменение краевых углов смачивания при растекании флюса по графиту и некоторым оксидам

Таблица 1. Температурные зависимости поверхностного натяжения флюса и краевых углов солевого расплава на графите и некоторых оксидах

\begin{tabular}{|c|c|c|c|c|c|c|c|}
\hline \multirow{2}{*}{$\mathrm{t},{ }^{\circ} \mathrm{C}$} & \multicolumn{6}{|c|}{ Расчетные и экспериментальные значения поверхностных свойств } \\
\cline { 2 - 8 } & \multirow{2}{*}{$\sigma_{\phi г}, \mathrm{мДж} / \mathrm{M}^{2}$} & \multicolumn{3}{|c|}{$\Theta$, град } & \multicolumn{3}{c|}{$\mathrm{W}_{\mathrm{a}}, \mathrm{мДж/ \textrm {M } ^ { 2 }}$} \\
\cline { 3 - 8 } & & $\mathrm{Al}_{2} \mathrm{O}_{3}$ & $\mathrm{SiO}_{2}$ & графит & $\mathrm{SiO}_{2}$ & $\mathrm{Al}_{2} \mathrm{O}_{3}$ & графит \\
\hline 1100 & 230 & 15 & 11 & 40 & 452 & 456 & 406 \\
\hline 1200 & 217 & 12 & 9 & 33 & 429 & 431 & 399 \\
\hline 1300 & 204 & 8 & 5 & 25 & 406 & 407 & 388 \\
\hline
\end{tabular}

$$
\begin{aligned}
& \sigma_{\phi г}=230-0,128(t-100), \\
& W_{a}=\sigma_{\phi г}(1+\cos \theta) .
\end{aligned}
$$

Из данных табл. 1 следует, что величина адгезии флюса к включению достаточно велика. Это означает, что флюс будет хорошо экстрагировать включения из расплава.

При расчете поверхностных свойств меди к флюсу использовали правило Антонова [7]:

$$
\sigma_{1,2}=\sigma_{1}-\sigma_{2}
$$

где $\sigma_{1,2}$ - межфазное натяжение на границе расслаивающихся жидкостей; $\sigma_{1}-$ поверхностное натяжение первой жидкости (расплав меди); $\sigma_{2}$ - поверхностное натяжение второй жидкости (солевой расплав).

$$
W_{a}=\sigma_{1}+\sigma_{2}-\sigma_{1,2}
$$

где $\mathrm{W}_{\mathrm{a}}$ - адгезия фаз при контакте двух взаимно насыщенных жидкостей (система медьфлюс).

Высокие значения межфазного натяжения меди на границе с солевым расплавом свидетельствуют о сильном притяжении поверхностных атомов меди объемом металла и сравни- 
тельно слабом взаимодействии их с ближайшими ионами флюса. Вместе с тем взаимодействие между металлической и солевой фазами не слишком слабое. Адгезия фаз, найденная по значениям поверхностного натяжения металла, равновесного с солью, меньше, чем в системе флюсвключение, и соответствует требованиям экстрагирования включения флюсом.

При расчете адгезии меди к включению использовали температурные зависимости поверхностного натяжения и краевых углов расплава меди на графите и некоторых оксидах, взятые из литературы [8].

$$
\begin{aligned}
& \sigma_{\text {эк }(\text { с } u)}=1300-0,264\left(t-1085^{\circ} \mathrm{C}\right), \\
& \theta_{C u-A l_{2} O_{3}}=238-0,081 t, \\
& \theta_{\mathrm{Cu}_{-} \mathrm{SiO}_{2}}=214-0,063 t \text {, } \\
& \theta_{\text {Си-графит }}=144-0,0017 t \text {. }
\end{aligned}
$$

Из данных табл. 3 следует, что работа адгезии меди к включениям имеет наименьшие значения.

На основании проведенных расчетов можно сказать, что флюс хорошо экстрагирует и удаляет включения из расплава.

Для приготовления композиционных сплавов системы $\mathrm{Cu}-\mathrm{Cr}_{3} \mathrm{C}_{2}$ использовали техническую медь марки М3, порошок хрома ПХ1С, а также наноразмерный алмазографитовый порошок (НП-АГ), полученный при детонации углеродсодержащих взрывчатых веществ.

\begin{tabular}{|c|c|c|c|c|}
\hline \multirow{2}{*}{ t, ${ }^{\circ} \mathrm{C}$} & \multicolumn{4}{|c|}{ Расчетные значения поверхностных свойств } \\
\hline & $\sigma_{\mathrm{Cu}-\mathrm{r}}, \mathrm{M} Д ж / \mathrm{M}^{2}$ & $\sigma_{\phi-r}, \mathrm{M} Д ж / \mathrm{M}^{2}$ & $\sigma_{\mathrm{Cu}-\phi}, \mathrm{MД} / \mathrm{M}^{2}$ & $\mathrm{~W}_{\mathrm{a}}, \mathrm{M} Д ж / \mathrm{M}^{2}$ \\
\hline 1100 & 1296 & 230 & 1148 & 378 \\
\hline 1200 & 1251 & 217 & 1116 & 352 \\
\hline 1300 & 1243 & 204 & 1121 & 326 \\
\hline
\end{tabular}

Сплавы системы $\mathrm{Cu}-\mathrm{Cr}_{3} \mathrm{C}_{2}$ получали в индукционной тигельной печи с графитовым тиглем. Зеркало расплава покрывали флюсом и после снятия шкала, без предварительного раскисле-

Таблица 2. Поверхностные свойства расплава меди на границе с флюсом

Таблица 3. Поверхностные свойства расплава меди на границе с графитом и оксидами алюминия и кремния

\begin{tabular}{|c|c|c|c|c|c|c|c|}
\hline \multirow{2}{*}{$\mathrm{t},{ }^{\circ} \mathrm{C}$} & \multicolumn{6}{|c|}{ Расчетные значения поверхностных свойств } \\
\cline { 3 - 8 } & \multirow{2}{*}{$\sigma_{\text {фг }}, \mathrm{MДж} / \mathrm{M}^{2}$} & \multicolumn{3}{|c|}{$\Theta$ град } & \multicolumn{3}{c|}{$\mathrm{W}_{\mathrm{a}}, \mathrm{MДж} / \mathrm{M}^{2}$} \\
\cline { 3 - 8 } & & $\mathrm{Al}_{2} \mathrm{O}_{3}$ & $\mathrm{SiO}_{2}$ & графит & $\mathrm{SiO}_{2}$ & $\mathrm{Al}_{2} \mathrm{O}_{3}$ & графит \\
\hline 1100 & 1296 & 145 & 149 & 142 & 234 & 185 & 275 \\
\hline 1200 & 1251 & 138 & 140 & 142 & 321 & 293 & 265 \\
\hline 1300 & 1243 & 132 & 133 & 142 & 411 & 395 & 264 \\
\hline
\end{tabular}




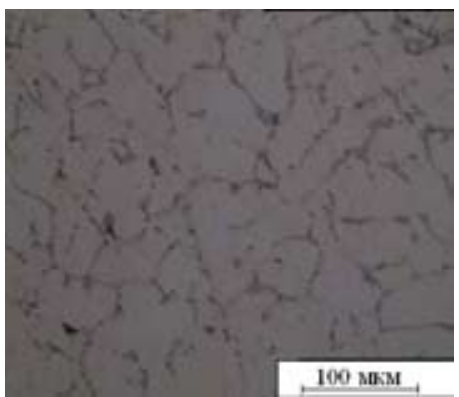

а) чистая медь

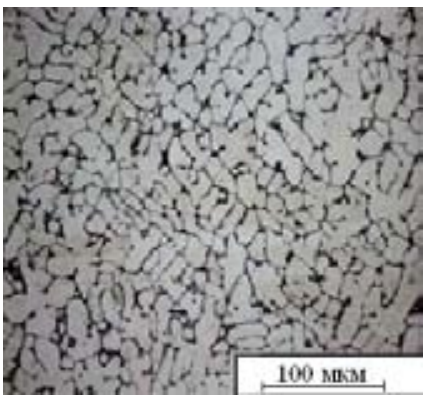

б) $\mathrm{Cu}-0,2 \% \mathrm{Cr}_{3} \mathrm{C}_{2}$

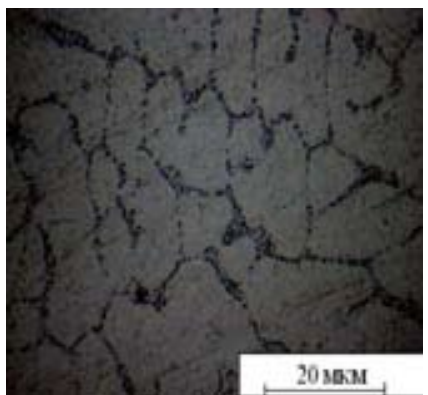

в) $\mathrm{Cu}-3 \% \mathrm{Cr}_{3} \mathrm{C}_{2}$

Рис. 3. Микроструктура литой меди (травл. $\mathrm{FeCl}_{3}$ )

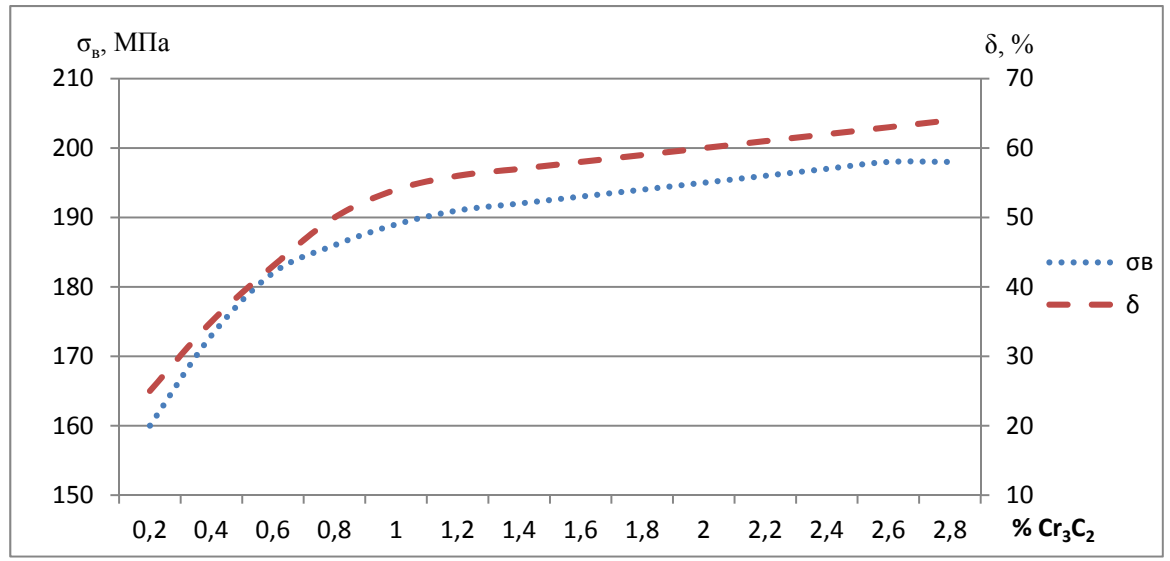

Рис. 4. Влияние содержания карбида хрома в литой меди марки М3 на предел прочности $\left(\sigma_{\mathrm{B}}\right)$ и относительное удлинение $(\delta)$

ния, при $1350{ }^{\circ} \mathrm{C}$ вводили в медной фольге с помощью колокольчика смесь порошкообразного хрома (фракции до 1 мм) и алмазографитового порошка для синтеза в системе карбида хрома. Расплав разливали в металлический кокиль и из полученных цилиндрических слитков готовили образцы для термического анализа, металлографических исследований и механических испытаний.

На рис. 3 представлена микростуктура полученных образцов с различным количеством карбида хрома. Анализ литой структуры свидетельствует, что небольшие добавки синтезированных в расплаве частиц карбида хрома выполняют роль модификаторов I рода, измельчающих зерно (рис. 3б). На рис. 36 изображена микроструктура образца с содержанием до 3 \% карбида хрома. Наблюдается достаточно равномерное распределение частиц по объему матрицы. Средний размер упрочняющей фазы менее 1 мкм.

На рис. 4 изображена зависимость содержания карбида хрома в литой меди марки М3 на предел прочности $\left(\sigma_{\mathrm{B}}\right)$ и относительное удлинение $(\delta)$.

Из приведенных данных следует, что с повышением содержания карбида хрома, синтезированного в расплаве меди, повышается прочность и в 2-3,5 раза возрастает пластичность 
медематричного композита по сравнению не только с пластичностью меди общего назначения, но и рафинированной фосфором катодной медью.

\section{Выводы}

Получен эффективный покровно-рафинирующий флюс, который защищает расплав меди не только от кислорода, но и от водорода.

Исследовано влияние содержания карбида хрома в композиционном материале на его физико-механические свойства.

Анализ литой структуры образцов с различным содержанием упрочняющей фазы позволил установить модифицирующее влияние при их небольшом количестве (до 0,2 мас. \%) на измельчение зерна. Повышенное содержание нано- и микроразмерных частиц $\mathrm{Cr}_{3} \mathrm{C}_{2}$ приводит к получению дисперсно-упрочненных медематричных композитов.

\section{Список литературы}

[1] Бабкин В.Г., Терентьев Н.А., Перфильева А.И. Литые металломатричные композиционные материалы электротехнического назначения. Журнал СФУ. Техника и технологии, 2014, 7(4), 416-423 [Babkin V.G., Terentev N.A., Perfilieva A.I. Cast Metal Matrix Composite Materials of Electrotechnical Purpose. J. Sib. Fed. Univ. Eng. technol., 2014, 7(4), 416-423 (in Russian)]

[2] Бодрова Л.Е., Гойда Э.Ю., Пастухов Э.А., Григорьева Т.Ф., Шубин М.А. Новые способы упрочнения хромовой бронзы. Перспективные материалы, 2014, 9, 66-71 [Bodrova L.E., Goida E.Iu., Pastukhov E.A., Grigor'eva T.F., Shubin M.A. [New methods for hardening chrome bronze. Perspektivnye materialy, 2014, 9, 66-71 (in Russian)]

[3] Мысик Р.К., Сулицин А.В., Брусницин С.В., Ожгихин И.В. Проблемы производства литых заготовок из меди. Журнал СФУ. Техника и технологии, 2014, 7(4), 394-399 [Mysik R.K., Sulitsin A.V., Brusnitsyn S.V., Ozhgikhin I.V. Problems of Copper Cast Bars Production. J. Sib. Fed. Univ. Eng. technol., 2014, 7(4), 394-399 (in Russian)]

[4] Бабкин В.Г., Трунова А.И. Технологические особенности получения и свойства медематричных композиционных сплавов электротехнического назначения. Tpydbl XII съезда литейщиков России. Нижний Новгород, 2015, 212-217 [Babkin V.G., Trunova A.I. Technological features of the preparation and properties matematichnikh composite alloys for electrical purposes. Proceedings of the XII Congress of Russian foundry. Nizhnii Novgorod, 2015, 212-217 (in Russian)]

[5] Ловшенко Ф.Г., Ловшенко Г.Ф., Лозиков И.А. Литые хромсодержащие бронзы, получаемые с применением механически легированных лигатур. Литье и металлургия, 2012, 3(67), 131-135 [Lovshenko F.G., Ловшенко Г.Ф., Lozikov I.A. Cast chromium-containing bronzes obtained with the use of mechanically alloyed ligatures. Foundry and metallurgy, 2012, 3(67), 131135 (in Russian)]

[6] Справочник металлурга по иветным металлам. Производство алюминия. М.: Металлургия, 1971, 560 с. [Handbook of the Metallurgist in non-ferrous metals. Production of aluminium. Moscow, Metallurgiia, 1971, 560 p. (in Russian)]

[7] Попель С.И. Поверхностные явления в расплавах. М.: Металлургия, 1994, 440 с. [Popel' S.I. Surface phenomena in melts. Moscow, Metallurgiia, 1994, 440 p. (in Russian)]

$$
-843-
$$


[8] Каниболоцкий Д.С., Верховлюк А.М., Железняк А.В. Взаимодействие меди, цинка, марганца и их сплавов с огнеупорными материалами. Процессы литья, 2015, 1 (109), 7-19 [Kanibolotskii D.S., Verkhovliuk A.M., Zhelezniak A.V. The interaction of copper, zinc, manganese and their alloys with refractory materials. Casting Processes, 2015, 1 (109), 7-19 (in Russian)] 